\title{
JUSTIÇA DE TRANSIÇÃO NO BRASIL: UMA ENTREVISTA COM NINA SCHNEIDER ${ }^{556}$
}

Gisele lecker de Almeida 557

A historiadora Nina Schneider é pesquisadora de pós-doutorado Marie Curie na Universidade de Konstanz, na Alemanha. Fez doutorado em História pela Universidade de Essex (Reino Unido), pesquisando a propaganda oficial durante o regime militar no Brasil. Se interessa por regimes autoritários em geral: como surgem, como são sustentados, e quais os legados que deixam para trás. Seu trabalho é melhor classificado como história social e cultural, e não apenas como história cultural. Isso porque não analisa produtos culturais em si, mas está sempre olhando para os interesses de poder e as dinâmicas sociais e políticas que sustentam o uso de determinados produtos culturais.

Revista Crítica Histórica Temos particular interesse em seu ponto de vista sobre as iniciativas de justiça de transição em curso no Brasil. Desde 1995, tivemos um movimento que pode ser percebido como uma re-memorialização do passado militar. Em seu artigo "Breaking the Silence," você fala sobre a política de silêncio em voga no Brasil dos anos 80 em diante: hoje poderíamos dizer que a "política de silêncio" do país é coisa do passado?

Nina Schneider Escrevi este artigo de volta de 2010, hoje seria um pouco mais sutil ao utilizar este conceito, porque é muito amplo. Naquele momento, eu queria descrever uma mudança na política oficial de memória levada a cabo pelo ministério de Direitos Humanos, sob a orientação de Paulo Vanucchi. Essa foi uma clara ruptura, em 2005, 2006: de repente, o governo começou a financiar oficialmente programas de memória, algo que nunca tinha acontecido antes. Este foi o momento que eu quis mapear nesse trabalho.

Hoje acho que podemos distinguir diferentes tipos de políticas oficiais de memória, e também dife rentes atores. Pode haver categorias que são mais úteis. Estou por exemplo pensando na terminologia de Rebecca Atencio (2014). Ela desenvolve o que eu disse no artigo, e acho que apresenta uma argumentação convincente para o termo "silêncio institucionalizado." Ela descreve a Lei de Anistia como tal, por ex emplo. Por outro lado, ela também fala sobre a memória institucionalizada, o que seria o tipo de política ofi cial de memória que descrevi em "Breaking the Silence". Entretanto, Atencio também analisa criticamente

\footnotetext{
${ }^{556}$ Entrevista realizada em Bruxelas, Bélgica, em 20/09/2014.

${ }^{557}$ Doutoranda em história pela Universiteit Gent (Bélgica), e bolsista da Coordenação de Aperfeiçoamento de Pessoal de Nível Superior (CAPES).
} 
as campanhas de memória oficiais como "memória institucionalizada", "reconciliação institucionalizada"... É uma coisa dizer que, de repente o Estado lança programas, mas é outra coisa analisar esses programas e o que exatamente estão fazendo - como estão representando o passado? Através da análise de políticas oficiais de memória, é possível perceber o quanto são problemáticas, pois enfatizam certos aspectos do passado, e silenciam outros.

\section{QUAIS PROGRAMAS GOVERNAMENTAIS VOCÊ TEM EM MENTE?}

Eu estava pensando no Direito à Verdade e Memórias Reveladas, cursos de direitos humanos para professores, a exposição itinerante sobre o regime militar que foi organizada, etc. Isso é algo que agora, três anos depois daquele artigo, eu buscaria distinguir: há diferentes atores dentro do Estado que estão fazendo diferentes tipos de política de memória.

Os projetos oficiais a que me refiro no artigo são do ministério dos Direitos Humanos, mas há outros. A Comissão de Anistia, uma organização diferente, ligada ao Ministério da Justiça, é responsável pelas re parações. As políticas de reparação no Brasil foram estabelecidas em duas fases. Houve as reparações por desaparecidos em 1995, que foram bastante limitadas, mas pessoas afetadas posteriormente puderam se candidatar através da Comissão de Anistia, que tem trabalhado desde 2001.

Em resumo, há diferentes agentes que fazem diferentes tipos de memória oficial. Este é um aspecto. Outro aspecto é: como esses programas de memória funcionam realmente? Eles silenciam certas questões e levantam outras questões.

Uma das conclusões centrais do trabalho de Atencio é que todos estes programas se encaixam nos parâmetros da reconciliação. Apesar de reconhecer que houve tortura e vítimas, nunca pedem a punição dos culpados. Este não é o caso quando falamos sobre a Comissão de Anistia, por exemplo.

Voltando a sua pergunta, acabou o silêncio? Diria que, certamente, temos visto uma mudança qualitativa neste âmbito. Houve diferentes fases: 1995 foi um passo importante, e as políticas oficiais de memória a partir de 2006 foram outro passo importante. E então temos o trabalho da Comissão de Anistia, especialmente as Caravanas da Anistia, que começaram em 2008 sob a liderança de Paulo Abrão. E, claro, a Comissão da Verdade (CNV) é também uma espécie de marco. Mesmo que ainda não saibamos como virá a ser julgada. 


\section{ENTÃO, O TERMO QUE VOCÊ UTILIZARIA HOJE É DE UMA MUDANÇA QUALITATIVA?}

Sim, eu usaria o termo de uma mudança qualitativa neste momento, porque a meu ver a grande questão é: como é que estas iniciativas narram a história? Quais são as lutas de poder agindo por trás des tas iniciativas? O que está por trás do interesse em selecionar certos pontos de vista e não outros? Então acredito que temos que ser muito mais específicos. O tema não é apenas a definição da agenda, mas também seu desenlace.

Será muito interessante acompanhar como as coisas podem mudar agora com as eleições. Como Marina Silva se posicionará com relação a esta questão. Ela disse que não revogaria a Lei de Anistia, mas posso lembrá-los que, quando Dilma concorreu à presidência, disse a mesma coisa. Então, nunca sabemos que tipo de tática está em jogo. Com relação à Lei de Anistia, ainda não se sabe qual é a verdadeira estratégia de Dilma, só saberemos isso em retrospecto. O que está muito claro é que os candidatos a presidente estão sob muita pressão política. Há muita coisa acontecendo nos bastidores que atualmente não vemos. Só seremos capazes de analisar estes eventos retrospectivamente.

\section{FALANDO UM POUCO SOBRE O CALENDÁRIO DE TRABALHO, A COMISSÃO DA VERDADE DO BRASIL CHEGA 22 ANOS APÓS O INÍCIO DA TRANSIÇÃO. POR QUE AGORA? SERÁ ESTE UM BOM MOMENTO PARA O BRASIL SE DEBRUÇAR SOBRE SEU PASSADO?}

Essa é uma boa pergunta, e também difícil de responder. Existem opiniões diferentes sobre se é um bom momento, e há diferentes explicações para o porquê da CNV estar acontecendo agora. A impressão seria a de que o processo no Brasil seja tardio. Historicamente, se você olhar para outros países da América Latina, o Brasil é realmente único neste sentido: a Argentina e o Chile estabeleceram comissões da ver dade logo após suas ditaduras, o Chile ainda teve duas comissões da verdade.

Alguns argumentam que é na verdade uma vantagem fazê-la mais tarde, porque os espíritos já se acalmaram, o Brasil hoje é uma democracia estável, não há perigo de tomada do poder pelos militares. Eu não estou muito certa de minha opinião sobre o tema, mas diria que a coisa mais importante é que o trabaIho seja bem feito. 


\section{E O QUE ISSO IMPLICARIA? O QUE SERIA CONSIDERADO UM TRABALHO BEM FEITO?}

A CNV tinha muito trabalho, e apenas dois anos e meio para dar conta de tudo aquilo - pouquíssimo tempo. Houve restrições: não sabemos ao certo os detalhes das restrições políticas, mas é evidente que os recursos humanos e financeiros foram limitados. A limitação estava já mesmo na fase de projeção da Comissão da Verdade, com a regra de que todos os comissários teriam que manter seus empregos. A CNV acabou sendo um emprego a tempo parcial, pois os comissários ainda estão exercendo suas funções e cargos anteriores. Numa visão crítica, este fato poderia ser lido como uma das estratégias utilizadas para enfraquecer a Comissão da Verdade.

Outro problema que ocorreu é que os membros da comissão entraram em uma série de conflitos. Não estou em posição de julgar, mas acho que o ideal seria uma comissão da verdade com uma equipe profissional, que colabora bem em conjunto, e não uma equipe que desperdiça o tempo com egocentrismo e este tipo de problemas. Outra crítica que tem sido frequentemente feita contra a comissão é que esta não tem colaborado muito bem com as comissões da verdade locais, grupos de vítimas e a sociedade civil em geral.

\section{É UMA CRÍTICA RECORRENTE A CNV SEU ISOLAMENTO?}

Sim. Há duas possíveis estratégias: uma é a transparência, e a outra seria a de conduzir a comissão à porta fechada. A estratégia que finalmente prevaleceu no Brasil foi a de portas fechadas. Cláudio Fonteles deixou a Comissão justamente pela falta de transparência.

É claro que, se você está informado sobre o acerto de contas do Brasil com a história, sabe que a transparência já vinha sendo um assunto muito debatido. Esta teria sido a melhor estratégia para abordar 0 passado, e ainda não sabemos os motivos para essa falta de transparência.

\section{A COMISSÃO DA VERDADE INSTIGA A PARTICIPAÇÃO DA SOCIEDADE CIVIL POR MEIO DE RECO- MENDAÇÕES PARA O RELATÓRIO FINAL POR PARTE DOS MOVIMENTOS SOCIAIS?}

Posso contar uma história sobre isso. Antes do início da Comissão da Verdade, em julho de 2012, houve uma reunião com membros da sociedade civil em Brasília. Acho que já havia um comitê local de trabalho antes disso, mas todos os outros ainda estavam por ser estabelecidos. Presenciei a cena, e o que 
aconteceu foi que cada membro da sociedade civil tinha apenas cinco minutos para falar. Fiquei chocada cada vez que foram interrompidos, especialmente quando estavam falando sobre experiências brutais: tor tura, abuso sexual... Após os cinco minutos, um dos comissários logo dizia: seus cinco minutos já acabaram! E este foi o primeiro encontro entre as vítimas, a sociedade civil e a CNV. Isso, certamente, não foi um tratamento ideal.

Os comissários poderiam ter funcionado melhor: ser mais profissionais, estar mais bem preparados, trabalhar melhor em equipe. Não acho que seja uma questão de ideologia; acredito que seja ainda mais básico que isso: não estavam preparados profissionalmente para tudo isso. Eles não pensaram sobre 0 que significaria convidar pessoas a contar suas histórias e, quando começam a falar, interrompê-las. Não é profissional. Houve muitas falhas técnicas, e esta não é a primeira comissão da verdade no mundo.

\section{VOCÊ SABE SE ALGUM TREINAMENTO FOI DADO EM PREPARAÇÃO? HOUVE REUNIÕES COM COMISSÁRIOS QUE TRABALHARAM EM OUTRAS COMISSÕES DA VERDADE, POR EXEMPLO?}

Houve um grupo de trabalho que preparou a proposta de lei, que teve uma formação. Priscilla Hayner e Eduardo González do Centro Internacional para a Justiça de Transição (ICTJ), por exemplo, estive ram em contato com este grupo. Então não é que não houve uma formação, mas eu não sei até que ponto. Isso também remonta a recursos: todas essas pessoas são ocupadas, tem cargos importantes. Acredito que o melhor cenário seria uma mistura entre uma equipe bem preparada, que tenha um compromisso real com a causa, e know-how profissional.

\section{O QUE SE PODE ESPERAR DO RELATÓRIO FINAL?}

Podemos esperar um relatório final com muitas recomendações concretas, algumas das quais são bastante previsíveis. Com certeza haverá uma sugestão de reforma na polícia, para coibir a tortura nas prisões. Isso é bastante claro, e eu acredito que não haverá disputas sobre isso entre os comissários. Eles com certeza reagirão à Lei de Anistia, a questão é como exatamente. Logo no início, durante a reunião que mencionei, a comissária Rosa Maria Cardoso já havia dito que haveria uma recomendação no relatório final de obedecer o Direito Internacional dos Direitos Humanos.

$\mathrm{Na}$ época, Cláudio Fonteles ainda estava na comissão, e ele era contra isso. Mas, mais tarde, ele deixou a comissão. Então, eu ficaria surpreendida se não recomendarem a revogação da Lei de Anistia. A 
revogação, ou alguma outra alternativa, pois não é necessário revogá-la para processar os criminosos. Existem diferentes maneiras no Direito Internacional dos Direitos Humanos pela qual se pode fazer isso. 0 Chile nunca revogou a Lei de Anistia, mas encontraram uma maneira de processar os militares.

No Brasil, o Supremo Tribunal Federal sempre bloqueou o assunto, e não apenas o Supremo Tribu nal Federal, mas os juristas em geral, muitos apoiam a Lei de Anistia. Há poucos advogados do Estado com a coragem e a vontade para defender a punição daqueles que cometeram tortura.

\section{HÁ NOTÍCIAS RECENTES SOBRE MILITARES SENDO PROCESSADOS NO CASO RUBENS PAIVA. VOCÊ ACREDITA QUE ESTAMOS VENDO UMA FLEXIBILIZAÇÃO DA LEI DE ANISTIA?}

A Lei de Anistia é controversa desde que foi promulgada. Este debate ganhou novo impulso a partir de 2007, quando houve uma primeira conferência organizada por Paulo Abrão, do Ministério da Justiça, para discutir a Anistia. Em seguida, tivemos a decisão do Supremo Tribunal de mantê-la, em 2010, e, sobretudo, depois que tivemos a condenação da Corte Interamericana de Direitos Humanos, em dezembro de 2011, e o Brasil ainda tem que responder a esta decisão.

As conclusões da CNV serão, provavelmente, parte desta resposta. Fábio Comparato, advogado de Direitos Humanos e professor emérito, argumenta que a Comissão da Verdade foi apenas uma manobra política para driblar a questão da Lei de Anistia. O Brasil não quer processar, e por isso, para poder dizer que está fazendo alguma coisa, criou uma comissão da verdade diluída, o que mostra uma espécie de vontade de responder.

\section{BIBLIOGRAFIA}

ATENCIO, Rebecca. Memory's Turn: Reckoning with Dictatorship in Brazil. Madison: The University of Wisconsin Press, 2014.

HAYNER, Priscilla. Unspeakable Truths: Confronting State Terror and Atrocity. New York and London: Routledge, 2001.

SCHNEIDER, Nina. Brazilian Propaganda: Legitimizing an Authoritarian Regime. Gainesville: University Press of Florida, 2014.

--------. 'Waiting for (an) "Apology": Has Post-Authoritarian Brazil Apologized for State Repression?', Journal of Human Rights, vol. 13, no. 1: 1-16, 2014.

-------.. 'Truth no more? The Struggle over the National Truth Commission in Brazil', Iberoamericana, vol. 42, pp. 164-170, 2011.

-------. 'The Supreme Court's recent Verdict on the Amnesty Law: Impunity in Post-Authoritarian Brazil', European Review of Latin American and Caribbean Studies, no. 90, pp. 39-54.2, 2011. 
--------. 'Breaking the "Silence" of the Military Regime: New Politics of Memory in Brazil?', Bulletin of Latin American Research, vol. 30, no. 2, pp. 198-212, 2010.

--------. 'Critical Reflections on Film as a Historical Source: A case study of the military regime in Brazil', Scope: An Online Journal of Film Studies (Scope e-Book), Issue 17, pp. 16-30, 2010. 